\title{
AS METÁFORAS DO CÂNCER E AS RESSONÂNCIAS DE UM CORPO DEFORMADO
}

\section{THE METAPHORS OF CANCER AND THE RESONANCES OF A DEFORMED BODY}

\section{Azemar dos Santos Soares Júnior*} azemarsoares@hotmail.com

RESUMO: Esse artigo tem por objetivo analisar o câncer enquanto uma doença responsável por alterar os roteiros de uma vida e problematizar a história de um corpo deformado. Para tanto, me aproximo da metodologia da ego-história por permitir escrever uma história a partir das minhas memórias, sendo aqui as principais fontes a serem analisadas. Uma escrita cheia de maus afetos, possíveis graças a História Cultural que possibilita analisar historicamente corpos, doenças, sensibilidades. Conclui-se que historicamente as doenças modificam as afetividades, o corpo, a vida do doente e dos que o cercam. São histórias e corpos corrompidos.

PALAVRAS-CHAVE: Corpo, Câncer, Memórias.

ABSTRACT: This article aims to analyze cancer as a disease responsible for changing the scripts of a life and to problematize the history of a deformed body. To that end, I approach the methodology of egohistory for allowing me to write a story from my memories, being here the main sources to be analyzed. A writing full of bad affections, possible thanks to Cultural History that makes it possible to analyze historically bodies, diseases, sensitivities. It is concluded that, historically, diseases modify the affectivities, the body, the life of the patient and those around him. They are corrupt stories and bodies.

KEYWORDS: Body, Cancer, Memoirs.

Abrindo as chagas da memória...

"Éramos felizes enquanto nada acontecia". A frase do escritor brasileiro Caio Fernando Abreu nunca soou tão bem para aqueles que presenciaram aquelas transformações. Metamorfose completa: virava o corpo ao avesso, tornava visível a miséria humana, fazia padecer a alma. O que mais inquietava não era o medo de como tudo acabaria - todos ali sabiam que um dia, de alguma forma, chegaria o fim - mas, como as transformações daquele corpo poderiam causar pavor e alimentar um sentimento que os humanos chamam de amor. Tudo parecia bem e feliz. Não há explicações para aquilo que conta essa narrativa. Vale aquele imperativo: "Existem acontecimentos que não combinam com explicações". Não seria possível explicar como uma massa de concreto ou uma dura pedra criou tentáculos dentro de uma parte qualquer do corpo e dali ganhou vida, cresceu fogosamente, auferiu poder e destruiu paulatinamente o corpo e a vida. Talvez não tivesse consciência de que destruir o outro fosse

\footnotetext{
* Doutorado em Educação (PPGE/UFPB). Pós-Doutorado em História pela Universidade Federal de Campina Grande. Atualmente é Professor Adjunto do Departamento de Práticas Educacionais e Currículo, na área de Didática e Ensino de História da Universidade Federal do Rio Grande do Norte (DPEC/UFRN), Campus Natal. É professor credenciado no Programa de Pós-Graduação em Educação da Universidade Federal do Rio Grande do Norte (PPGEd/UFRN) e ao Programa de Pós-Graduação em História da Universidade Federal de Campina Grande (PPGH/UFCG). Sócio efetivo do Instituto Histórico e Geográfico do Rio Grande do Norte (IHGRN).
} 
também sua destruição. Um tipo de pedra que lança sobre o corpo uma maldição: deforma, definha, mata.

A história que vou contar, não é feliz. Esse sentimento não combina com trajetórias que terminam com morte e dor. Ao longo da história da humanidade nos deparamos com histórias ditas extraordinárias, como aquelas tecidas por Edgar Alan Poe onde seus personagens são corpos adoecidos que proclamavam o terror. A descrição dos corpos apresentados nessas histórias parecia descrever um cadáver: lábios finos, olhos fundos e torneados por olheiras, pele pálida, tato gélido, fisionomia de constantes ataques epiléticos, imagem que surpreendia e horrorizava.

A personagem que apresento, foi como Berenice ${ }^{1}$ : um dia qualquer foi surpreendida por uma doença fatal que a atingiu como um vento maléfico, e, tudo mudou. Uma terrível transformação fez brotar em seu corpo. A doença penetrou seu interior, modificou seu caráter, dilacerou seus hábitos e ceifou sua vida. A pedra de concreto, metáfora de um câncer cerebral, apresentou-se como uma visita indesejada, má intencionada apoderou-se como rei em seus aposentos, fez surgir um terrível mal para o corpo, um câncer na alma. Uma história da dor.

Repito: eram felizes. Até o dia em que aquela doença alterou seus destinos. Não quero aqui discutir a doença pela doença, sua origem, suas formas de curar ou medicar, mas os impactos que ela causa na vida das pessoas. Apresento nas entrelinhas desses escritos as zonas infestadas pelas mazelas que degradaram a vida, estereótipos criados por uma doença que afeta cada dia mais pessoas espalhadas pelo mundo: o câncer. A partir da história individual dessa personagem, busco entender como os roteiros da vida podem ser modificados através das marcas no corpo. Para tanto, mergulho em minhas memórias para transformar em narrativa histórica aquilo que vivi e convivi: o câncer de minha mãe e o padecer de seu corpo.

\footnotetext{
${ }^{1}$ Conto de autoria de Edgar Alan Poe, publicado originalmente no livro "Histórias extraordinárias".

${ }^{2}$ Chamava-se Maria de Fátima do Nascimento Santos. Nasceu em 23 de outubro de 1952. Casou e deu à luz a quatro filho. Formou-se em Pedagogia pela Universidade Federal da Paraíba. Dedicou sua vida a tarefa de alfabetizar crianças e as lutas por melhorias no bairro que viveu por quase quarenta anos. Trabalhou por longos anos como servidora pública do município de Santa Rita e do Estado da Paraíba. Foi diagnosticada com câncer no cérebro no início do ano de 2011. Lutou bravamente para sobreviver.
} 
Escrever, como sugere Durval Muniz de Albuquerque Júnior (2013) se configura enquanto uma possibilidade de se apartar de si mesmo, de se perder, de se desconhecer, de experimentar o que está para além da memória e da história, a experimentação permanente do indeterminado, do indefinido, do incondicionado. Um exercício de desprendimento da vida. Escrever pode ser colocar a vida no pensamento, no sentido de procurar dar a ela a sua melhor representação, pode ser a busca da mimese, da cópia da vida no pensamento; mas pode ser colocar a vida no pensamento, no sentido desta servir de teste, de servir de desafio ao próprio pensamento, uma vida que se escreve para desafiar o pensamento, para incitá-lo a se ultrapassar.

Assim, escrevo essa história na tentativa de me libertar das dores ainda provocadas pelas lembranças. Para exorcizar as sequelas daquele tempo de tristeza e aprender a conviver com a saudade. Escrevo para revelar meu caráter de finitude, minhas fragilidades. Escrevo para encarar de frente as dores de minha história. Escrevo para seguir adiante.

Trata-se de uma história de si embaralhada a história de minha mãe. Uma autobiografia do que vivi com ela. Uma ego-história, ou uma história de mim e do outro a partir das minhas lembranças. Uma tentativa de explicar parte de minha história como se fosse de outrem, exercício metodológico de tentar aplicar a si próprio o olhar frio, englobante e explicativo que tantas vezes lancei sobre os outros. Em resumo, tornar claro, como historiador, a ligação existente entre a história que cada um fez e a história de que cada um é produto (Cf. NORA, 1989). Essas memórias se apresentam em forma de arquivo secreto, dolorido, amargurado, aquilo que Arlete Farge (2017, p. 13) afirmou jamais ser exposto caso não fosse a ocorrência de uma fato social perturbador. Arquivo que revela um não dito por ser essencialmente sentido. Uma brecha no tecido dos dias, a visão de um fato inesperado. Memórias de personagens comuns, raramente visitados pela História.

A escrita desse texto tem por objetivo analisar o câncer enquanto uma doença responsável por alterar os roteiros de uma vida e problematizar a história de um corpo deformado. Uma doença nada silenciosa, responsável por deformar um corpo e fazer emitir sonoridades em forma de alarme: gritos da dor. Imagens da minha memória que gravaram através da visão a contorção do corpo, o atrofiamento das articulações, as mudanças de cor; que sentiram os humores do corpo que não mais havia forças para cuidar de si e passou a depender do outro; pelo tato que segurou aquele corpo que não mais possuía forças para se 
manter de pé; nos timbres que falhavam pela voz roubada, mas que insistia em ecoar alertando as agruras que dilaceravam seu corpo. São essas, as minhas memórias, servidas à mesa em forma de discursos problematizados. Soma-se a essas, outros discursos, escritos e/ou imagéticos: exames médicos que anunciavam o mal, atestados que asseguravam o poder da doença, imagens que exibiam a fogosa massa de concreto, ressonâncias das entranhas que revelavam a necessidade de incisões, extirpações, mutilações. É sobre esses discursos que faço também incisões, produzindo outros discursos, outras deformidades.

Como chama atenção Sandra Pesavento (2005, p. 15) o olhar de Clio mudou e voltouse para outras questões e problemas, para outros campos e temas. Assim, produzir história a partir das experiências vividas, sobre os sentimentos mais íntimos tornou-se possível quando se trabalha com a ideia de resgate de sentidos conferidos ao mundo e que se manifestam em palavras, discursos, imagens e práticas. Uma história repleta de sensibilidade que "se traduz em sensações e emoções, na reação dos sentidos afetados por fenômenos físicos ou psíquicos, uma vez entrado em contato com a realidade" (PESAVENTO, 2007, p. 10). Narrativa costurada pelas linhas da emoção, das sensações da dor revivida através da lembrança, das experiências sentidas e vividas e que aqui se apresentam como atividade reflexiva. Uma história do tempo presente, aquela responsável por tratar a interpretação do tempo próximo do acontecimento, na qual se recorre aos depoimentos/memórias de pessoas vivas (Cf. TÉTART, 2000, p. 133). Assim, recorrer as próprias memórias é cair em armadilhas, por esta preso na rede de uma história que é parte sua. Assumo a tarefa de desembaraçar o emaranhado das minhas subjetividades e me coloco sob julgamento.

Essa história representa o despedaçar de meus medos. Ela destoa daquelas histórias sisudas produzidas por historiadores pelo fato de não se apoiar em nenhuma constância, pois acredito que nada é fixo, cristalizado ou absolutamente verdadeiro. Nessa história, denuncio o silêncio em que me aprisionei durante anos. Construo uma narrativa histórica que em alguns momentos não foi possível interpretar, devido a uma espécie de terror contidos no discurso produzido que arrasta com ele dor e morte. Por vezes, fiz como Michel Foucault (2003) diante do Caso Rivière, entendi o discurso como um acontecimento histórico, outro acontecimento elaborado a partir do fato vivido.

Discurso sobre um destino implacável. Talvez essa expressão seja adequada para definir a doença problematizada, ou melhor, as figuras de linguagem sobre a doença. Digo, 
sobre essa pedra de concreto que mata e que popularmente chamamos de câncer. Uma enfermidade, que segundo Susan Sontag (2007, p. 12) entra sem pedir licença. Bárbara invasão. Invisível. Na maioria dos casos, sentença de morte. Uma doença que antes de padecer eternamente o corpo faz surgir as marcas da fragilidade humana, dai, todo o temor instaurado, especialmente numa sociedade do espetáculo, em que aparência física é fundamental. O câncer desfigura. Acentua os silêncios.

Uma doença repleta de figuras de linguagem. Um corpo que apodrece, se entorta e se contorce, grita de dor, geme e perde a cor, cria manchas, escurece a visão, faz sumir a audição e a voz, sucumbe. Trata-se de uma história que dá vida a calamidade, ao pavor, as zonas noturnas do corpo: a doença. É uma história de intimidade, de descrição das afetividades, possível apenas no campo da História Cultural por suas novas tendências de abordagem do real passado.

Enquanto buscava-se esconder do público o corpo adoecido, não pelo contágio, já que a doença não oferece contaminação, mas pelo pânico que ela podia causar, contarei nessas linhas a experiência vivida nos domínios privados da família atingida pelo câncer. A personagem central dessa história conviveu com a doença durante os dois últimos anos de sua vida. Fez aqueles que estavam em seu entorno, verem seu corpo sofre a metamorfose da dor através da deterioração corporal. Metáforas que problematizaremos. Narrativas de pavor, sofrimento e morte.

\section{Fendas na memória, fissuras no corpo}

Parecia ser um dia comum se não fosse as fortes dores de cabeça que alteravam o dia de intenso trabalho. Não fazia muito tempo, as dores na cabeça tornaram-se constante e nos mais diversos níveis. Por vezes, ao ensinar as lições aos seus alunos, passou a sentir enjoos seguidos de dores; ou mesmo em casa numa atividade qualquer. Como trabalhadora que sempre foi, acreditava que não podia parar. A dor não merecia sua atenção. Para tanto, anestesiava-se com analgésicos, que como bons paliativos, rapidamente surtiam efeito. Seu corpo começava a denunciar aquilo que sua razão não queria admitir. Protelava entre um comprimido e outro uma consulta médica. Alegava que sua pressão arterial estava subindo devido aos intempéries cotidianas. 
Não tardou para que as drogas vendidas na farmácia mais próxima parassem de fazer efeito. O quadro rapidamente evoluiu para dores mais fortes seguidos de enjoos e vômitos. Numa tarde ensolarada de fins de setembro de 2010, entramos de mãos dadas no hospital gerido pelas irmãs carmelitas na cidade de Santa Rita - PB. Apesar das cólicas, me olhava com carinho e sorria. Durante a consulta médica, o esculápio alegou um quadro de estafa seguido de desidratação. Orientou a internação para recuperar o corpo das perdas sofridas ao longo dos últimos dias. Medicada e bem acomodada, sua residência hospitalar enchia-se de amigos e familiares. Lembro com dor a última vez que seus olhos fitaram os meus. Tarde da noite, ao sair do seu quarto, comecei a fechar a porta. Por entre o espaço que se comprimia, ela olhoume. Titubeou com a boca um "eu te amo". Fechei a porta. Iniciava a via crucis que revelaria as misérias de seu corpo. Seu padecer em vida.

A manhã seguinte trouxe consigo a dor da possibilidade da perda. As primeiras notícias ouvidas não faziam sentido. Palavras como "desacordada", "sem movimentos", "sem consciência" aplicavam golpes as minhas emoções que se revelavam em dores do meu corpo. Medo e desespero marcaram aquele dia. A maldição da massa de concreto começava a revelar seu poder, a (des)governar um corpo dito sadio. $\mathrm{O}$ toque do telefone parecia anunciar o início do fim: chegava a notícia da transferência para um hospital com mais recursos para tratar aquilo que os médicos alegaram ser uma desidratação: o Acidente Vascular Cerebral Hemorrágico (AVCH).

Encontrei seu corpo numa maca de corredor de hospital. Seu semblante apático imperava. Os cabelos louros não mais mexiam com o vento. Seus olhos azuis não brilhavam. Braços e pernas não tinham movimentos. Os coágulos de sangue que se formaram atingiram uma sensível região do cérebro que impediam os movimentos de partes do corpo. Por fora, víamos apenas um corpo esmorecido. O corpo escondia os infortúnios dentro de sua intimidade. Um corpo que dentro de si, sangrava. Jorrava de forma danosa o líquido que sustentava a vida.

O Hospital Estadual de Emergência e Trauma Senador Humberto Lucena ${ }^{3}$, tornou-se a nova morada de nossa família. Era lá que iriamos passar longos dias de angústia, esperança

\footnotetext{
${ }^{3}$ O Hospital Estadual de Emergência e Trauma Senador Humberto Lucena está localizado na Avenida Orestes Lisboa S/N, conjunto Pedro Gondim, na cidade de João Pessoa - PB. Fundado no ano de 2001, o referido hospital tem como finalidade especifica operacionalizar a gestão e execução das atividades e dos serviços de saúde de
} 
e dor. Lugar onde ouvi contar histórias tão amargas quanto aquela que vivia. Espaços em que cartografei minhas dores partilhadas nessa história. Memórias azedas. Fel que não foi possível esquecer.

Foi dentre paredes manchadas de dor e arquitetadas para salvar vidas, que a notícia parecia ceifar nossa esperança. $O$ anúncio da médica neurologista soou seco como o dia num deserto. Parecia falar de um copo que se quebrou e a água que se esvaiu. Metáfora de uma coleção de maldizer: "a paciente possui um coágulo de sangue provocado pelo AVCH"; "precisa ser operada com urgência"; "o quadro é gravíssimo, dificilmente sobreviverá"; "caso sobreviva a cirurgia, bom rezar para que viva as 24 primeiras horas"; "Caso viva as 24 horas, fato improvável, talvez sobreviva"; "Poderá ter todas as sequelas". Trazia em mãos um laudo acompanhado de imagens. As palavras escritas asseguravam a existência de uma "extensa área espontaneamente hiperatenuante (sangue), circundada por halo hipodenso (edema) acometendo a substância brancas e região subcortical dos lobos parietal, temporal e accipiptal direitos [...] extensa hemorragia parenquimatosa" (Tomografia Computadorizada do Crânio, 23 set. 2010). Ouvia e lia tudo de forma atordoada. Em silêncio, meu corpo que não foi educado para a dor, tremia. Metáfora de minhas fragilidades. Nos restava clamar a misericórdia divina.

Repito, essa é uma história da dor, portanto, uma história do corpo propriamente dito. Acerca do entendimento da dor, preciso comungar com Alain Corbin (2008, p. 330): é uma experiência subjetiva, um evento psicológico que se inscreve no corpo e modela a memória. As práticas da dor pessoal, as maneiras de ouvi-la, de senti-la, a forma como é acolhida e exprimida, formam aos poucos a identidade do sujeito. Através da dor, lê-se a história do indivíduo. A dor chega inclusive, a estruturar a vida. Ela pode paralisar o pensamento e modificar a relação com os outros. A dor causa sofrimento, aquele sentimento que se abre a reflexividade, ao questionamento, ou como afirmou Marie-Jeanne Lavilatte (1999) o sofrimento é uma dor suscetível de ser vista e olhada.

Do lado de fora, não ouvimos o ruído da serra que cortava o crânio que abria sua cabeça e desfigurava seu corpo, mas ouvimos o tilintar do relógio por longas horas de espera e angustia. Tinha naquele momento, consciência que seu corpo não sentia dor, pois estava

urgência e emergência em trauma, uma vez que é um referencial dessa área no Estado da Paraíba (Cf. GRIGÓRIO, 2005). 
anestesiado ${ }^{4}$, inerte, paralisado. Sabia que a anestesia propiciava aos médicos "um novo conforto: o silêncio, a imobilidade do paciente e a rapidez na intervenção" (CORBIN, 2008, p. 340). Alguns desses instantes não podem ser revividos por meio das lembranças. Tenho a impressão que diante de tamanha dor, a memória acabou por fazer fendas responsáveis pelo esquecimento de detalhes, ficou apenas a marca da dor. As parcas lembranças são do tremor do corpo e dos espaços pequenos para pernas que andavam para lá e para cá. O início da noite fez abrir a porta que deu passagem a médica responsável pela cirurgia: tudo ocorreu dentro da normalidade, mesmo o caso ainda sendo gravíssimo. Um silvo de alívio soou em meu corpo. O corpo dela, em coma induzido pelas gotas de midazolam que adentravam por suas veias, já estava acomodado na Unidade de Tratamento Intensivo (UTI).

O primeiro passo dado dentro da UTI, parecia me conduzir para dentro de uma geladeira: branca, clara, fria. Os sons das máquinas zuniam meus ouvidos. As camas dispostas em ordem sequencial revelavam a ordem disciplinar daquele espaço (Cf. FOUCAULT, 2009). O fardamento dos funcionários seriam iguais se não fosse as diferentes cores que indicavam suas funções. O psicólogo guarnecido na porta de entrada era responsável por distribuir os bilhetes de entrada, por transmitir notícias, por anunciar as mortes. Enfermeiras solicitas andavam de um lado para o outro atendendo aos pedidos, intercorrências (que eram comuns), e, aflições. Médicos, sisudos, quando chamados eram comedidos, de poucas palavras, dedicavam a maior parte do tempo a olhar de cima, de seu lugar de poder, a supervisionar. Sua boca ao falar, parecia revelar sentenças.

Foi durante o horário de visita noturna que adentrei aquele espaço tão frio quanto meu corpo amedrontado. Precisei segui reto passando por todas as camas até chegar ao último leito. Lá, ela estava. Deitada, em sono profundo. O rosto e as mãos muito inchados. A cabeça visivelmente raspada e envolvida com faixas que compunham um grande curativo. Por um instante, tomado pelo espanto, quase não reconheci aquele corpo que me gestou e animou minha vida. As informações eram parcas, as incertezas, numerosas. Toquei suas mãos. Membros de um corpo que atrofiava-se.

\footnotetext{
${ }^{4}$ Conforme Alain Corbin (2008) a anestesia colocou fim ao espetáculo da dor reservado a um pequeno número de indivíduos; um espetáculo sonoro pontuado por gritos assustadores, urros que, no dizer dos próprios cirurgiões, não se podia controlar; um espetáculo visual alimentado pelas contorções, o desvario do paciente que não parava de debater-se e, mais que isso, pelo derramamento de jatos de sangue. A cirurgia era também um espetáculo da angustia e do desespero, tendo em vista as terríveis taxas de mortalidade pós-operatória.
} 
Ao completar as primeiras vinte e quatro horas, recebi a notícia de que seu corpo seria mais uma vez aberto, suas entranhas remexidas. Fazia-se necessário uma craniotomia descompressiva ${ }^{5}$. Devido a formação do coágulo e a cirurgia, o cérebro estava bastante inchado e precisava de espaço para expandir. As tomografias, donas de imagens disformes, orientavam os médicos a tomar a decisão sobre o procedimento a seguir. As lembranças ruins e a angustia vivida foram novamente revividas. Todo o perigo retomava. Voltávamos ao ponto inicial.

Após longas horas de cirurgia para retirada de parte direita crânio, seu corpo inerte, servido em banquete para aqueles que o deformavam, foi trazido de volta a sala fria e apática. As sala branco clim. Lugar de guerra. Guerra contra vírus e bactérias. Batalha contra a morte. Como lugar de luta, exigia ordem. Peleja silenciosa. Silêncio rompido apenas pelos grunhidos de dor das famílias ao receberem as notícias do padecer. Era para aquele espaço gélido, árido de sentimentos que seu corpo retornava. Precisava dos cuidados que só poderiam ser ofertados ali. Com um terço em mãos, rezei seguidamente em silêncio.

O atestado médico contendo informações sobre seu quadro de saúde foi-me entregue no dia seguinte. Ele certificava que "a paciente Maria de Fátima do Nascimento Santos, 57 anos, encontra-se internada na UTI deste hospital, submetida a procedimento cirúrgico de grande porte, sem previsão de alta (CID:10 - I 60.06)" (Atestado Médico, 28 set. 2010). Sem mais, seguia a assinatura do médico plantonista. Era um documento técnico, procedimental, comum aquelas pessoas que ali trabalhavam. Era a confirmação da possibilidade de perda, para os familiares.

Com o passar dos dias o corpo desinchava fazendo aparecer traços reconhecidos aos olhos que tanto viram outrora. Reduzido o volume provocado pelas inflamações, o corpo ainda era disforme: os movimentos do lado esquerdo do corpo não mais possuíam movimentos, a visão periférica havia falecido, a fala fraturada, as lembranças esquecidas. As sequelas do acidente vascular ganhavam visibilidade. Seu corpo agora ganhava outros remelexos: dos fisioterapeutas. Buscava-se recuperar os estímulos para que seus movimentos

\footnotetext{
${ }^{5}$ De acordo com Faleiro (2005) a craniotomia descompressiva (CD) é método cirúrgico para redução imediata da pressão intracraniana (PIC). Geralmente é indicada em casos de tumefação cerebral (TCe) e hematoma subdural agudo (HSDA) ou mesmo para lesões não traumáticas.

${ }^{\mathbf{6}}$ Hemorragia subaracnóide proveniente do sifão e da bifurcação da carótida.
} 
retornassem. Aos poucos, recuperava-se. As falanges dos dedos pouco a pouco ganharam vida. Os exercícios da fisioterapia e fonoaudiologia colaboravam decisivamente no processo de recuperação. Os médicos e enfermeiros acompanhavam de perto o controle da pressão arterial.

Visita a visita me faziam ter esperança em leva-la de volta para casa. Dias ruins eram surpreendidos por dias felizes. Aos poucos um sorriso torto nos lábios traziam uma alegria sem tamanho. Mas, a sala fria ofertava outros riscos. Era uma geografia povoada por doenças, uma labuta diária entre saúde e enfermidades. Bactérias pareciam ganhar forças e adentrando corpos como hospedes indesejados, instalavam-se provocando outras enfermidades. $\mathrm{Na}$ maioria das vezes, as bactérias embrenhavam-se pelos tubos colocados garganta abaixo para assegurar a respiração mecânica. O tubo de ar, as conduziam direto ao pulmão. Instaladas, provocaram uma pneumonia. Exposto, seu corpo foi vítima de uma infecção hospitalar.

Sem surtir efeito, antibióticos eram aplicados de forma venosa. As secreções aumentavam. Precisava-se descobrir o tipo de bactéria e o mais potente medicamento para vencê-lo. O tubo invasivo não podia mais permanecer instalado pela boca. A orientação médica foi realizar uma traqueostomia ${ }^{7}$, mais um procedimento responsável por cortar e adentrar o corpo. Mais uma deformação. Mais um roteiro alterado. Após seguidas aplicações de antibióticos, seu corpo vencia a pneumonia. Ganhava o bilhete de alta, o retorno para casa. Foram trinta dias na sala fria. Trinta dias de sofrimento e dor. Traumas trazidos na memória.

\section{Corpo traído, corpo consumido}

O dia 23 de outubro sempre foi de festa na casa de número 54. Era o dia de comemoração da vida dela. Desde seu nascimento em 1952, o vigésimo terceiro dia desse mês era de alegria. Nesse mesmo dia do ano de 2010, comemorávamos sua vida com seu retorno para casa. Festejávamos em data tão oportuna seu renascer. Ela estava entre nós, nos recônditos da nossa intimidade. Não houve uma festa no sentido literal da palavra. A festa foi em nossos corações. A gratidão era tamanha que não haviam contas suficientes no rosário para rezar a Ave-Maria. Eu estava tomado pelo sentimento de vitória. Em casa, o tratamento

\footnotetext{
${ }^{7}$ Intervenção cirúrgica que consiste na abertura de um orifício na traqueia e na colocação de uma cânula para a passagem de ar.
} 
continuava diariamente. Cuidávamos para que as cicatrizes do corpo fossem curadas. Colocávamos, sobretudo, curativos nas cicatrizes da alma.

Essa, tinha tudo para ser uma história de superação, de vitórias contra as enfermidades. Mas não foi. A alegria que contagiava a casa estava fadada a uma duração efêmera. O que estava por vir, era invencível, inabalável, puro concreto, duro, rijo. Concreto que matava. Pedra que criou raízes tão rígidas quanto seu corpo. Maldição personificada em sólida argamassa. Tentáculos de cimento que se infiltrava nos mais íntimos dos espaços. Seixo disforme. Câncer.

O mês de novembro do mesmo ano possuiu uma pseudo-calmaria. Seu corpo remendado por tantas linhas e agulhas e revirado pelas imagens de tomografias começou a expelir as secreções da miséria: um caldo verde, pavoroso, sua bílis. Os vômitos tornaram-se constantes. Na primeira semana, três quatro vezes; na segunda semana, duas três vezes ao dia; na terceira semana, num intervalo dentre minutos. Não havia medicação que impedisse as náuseas seguidas de lanços. Numa noite de quinta-feira do final de novembro, retornamos para o hospital. Seu corpo mais uma vez foi submetido a máquina de fabricar imagens pavorosas: o tomógrafo. Já com o coração nas mãos, aguardei nos corredores brancos do pronto atendimento o resultado.

Já passava da meia noite quando vestindo um jaleco branco, o médico se aproximou com uma pasta verde. Ali estava escrito a sentença. O médico assumia o lugar do algoz juiz, implacar. Aquele que anuncia o infortúnio. Suas palavras fizeram meu chão desabar. Por instantes quis não acreditar no laudo: "um tumor localizado no cérebro". Todo o acontecido nos meses anteriores se passaram como um filme de terror. O texto timbrado em lágrimas e sangue naquele papel, revelavam uma "formação expansiva heterogenia, sólido-cística, com sinal predominantemente hipointenso em T1 e hipointenso em T2, apresentando áreas de marcado sinal hipointenso em T2 [...] observa-se realce irregular pelo meio de contraste, com áreas de alta perfusão e outras de degeneração cística/necrótica de permeio [...] mastoidite direita" (Tomografia cerebral, 18 dez. 2010).

De imediato afirmei ser impossível, pois ela tinha tido um acidente vascular cerebral hemorrágico e que haviam feito várias tomografias e cirurgias. Portanto, se havia um tumor, teria aparecido tanto nas imagens do exame, quanto no ato da cirurgia para retirada do coágulo. Ainda de pé naquele gélido corredor, o médico retrucou afirmando que tudo tinha 
sido causado pela ação da funesta pedra de concreto. Ela causou o AVCH e agora estava causando os vômitos. Que o tumor não fora visto devido ao sangramento e ao inchaço do cérebro responsáveis por escondê-lo. A verdadeira causa estava exposta, revelada, desnudada: uma maldita pedra plantada no cérebro dela.

Seu corpo estava muito debilitado. Não suportaria por muito tempo os vômitos constantes. Alimentar-se era tarefa impossível num momento em que o corpo expulsava até o que não possuía! A orientação médica foi a imediata cirurgia para retirada do tumor, ou de parte dele. Afirmou com veemência, que seu corpo só resistiria por mais quarenta e oito horas. O cronômetro tinha disparado. Precisei correr para tentar salvá-la.

Não seria possível aguardar a cirurgia através do Sistema Único de Saúde (SUS), portanto, restava realizar a cirurgia num hospital privado. Encaminhado para um médico neurologista, daqueles considerados renomados nesse tipo de intervenção cirúrgica, tivemos uma rápida conversa, da qual, algumas de suas frases soltas, saltam em minha memória: “[...] pela idade dela e pelo delineamento do tumor nas imagens a probabilidade é que seja maligno"; "[...] é preciso fazer uma ressonância magnética para obter imagens com mais precisão"; "[...] a cirurgia, sem nota fiscal custa quarenta mil reais"; "[...] o risco de morte durante a cirurgia é muito alto". Marcamos a cirurgia para o dia seguinte. Tive menos de vinte e quatro horas para levantar o dinheiro. Me vi clamando ao gerente da agência bancária o empréstimo. No fim da tarde de sexta-feira estava com o dinheiro em mãos.

Era um sábado nublado. Acordamos cedo. Seguimos para o laboratório onde seria realizada a ressonância magnética. Seu corpo mais uma vez era desnudado pela tecnologia das máquinas que escaneavam suas entranhas. Um corpo posto ao avesso. Imagens que amedrontavam. Deformidades existentes dentro de si. Tomografias da aflição. Aquilo que estava em sua cabeça foi impresso em plástico transparente. Daqueles que precisamos erguer sob a luz para ter a visão perfeita. Cenas de uma pedagogia da dor. Práticas educativas da amargura. Atroz destino responsável por alterar os roteiros da história de minha família.

As imagens eram transpostas para o papel em forma de escrita. O laudo médico pouco diferenciava-se da tomografia feita dois dias antes: "Lesão expansiva fronto-têmporoparietal direita que compromete o núcleo capsular ipsilateral, com aspecto sólido-cístico, com sinal heterogêneo predominantemente hipointenso medindo cerca de 6,8 x 6,1 cm" [...] "o 
corpo caloso apresenta morfologia e sinal mantidos" [...] "lesão expansiva diagnosticada como glioma de alto grau: mastoidite à direita" (Ressonância magnética do encéfalo, 20 dez. 2010).

De posse dessas imagens, partimos para o Hospital Memorial São Francisco, local em que foi realizado a cirurgia. Antes de aplicar a dose que a faria dormir, segurei suas mãos, olhei nos seus olhos. Balbuciei qualquer coisa como um "eu te amo". Segurei a dor, as lágrimas, o desespero. Vi seus olhos fecharem. Seu corpo era levado para a mesa de sacrifícios. Dentro daquele quarto, cai em desespero.

Horas depois, sou chamado ao corredor que dava acesso a sala de cirurgia. O médico afirmou ter sido a cirurgia tranquila e sem intercorrências. Que devido a região em que se localizava o tumor, só foi possível retirar cinquenta por cento de sua estrutura. Estendeu a mão em minha direção entregando-me um pequeno recipiente plástico com um líquido transparente e um pedaço de pedra. Estava em minhas mãos um pedaço do câncer. Era o carrasco. Aquele que precisava agora ser analisado, remexido, desnudado. Que seria submetido ao exame de biópsia.

Foram 24 horas de intenso cuidado na UTI. Em seguida, dois dias no quarto de repouso. Voltamos para casa. Iniciamos novamente o acompanhamento de fisioterapia e fonoaudiologia, os cuidados com as cicatrizes da cirurgia e os adesivos da alma. Já se aproximava o fim do ano de 2010. Precisávamos estar reunidos para passar aquele que poderia ser o último festejo natalino juntos. Após poucos dias de cuidado e troca de afetos, recebemos o resultado do exame: o tumor era maligno. Um glioblastoma multiforme ${ }^{8}$, conhecido pelos médicos como GBM.

\section{As metáforas da deformação}

A tarde cinzenta do dia cinco de janeiro de 2011 trouxe consigo o anúncio do atroz destino: "Gliobastoma multiforme (astrocima grau IV na classificação da OMS)" (Exame anatomopatológico, 05 jan. 2011). As palavras escritas naquele folha seca de papel não fazia sentido para aqueles que de medicina nada entendiam. Apenas uma frase fez corroer minha alma e provocar dores no meu corpo: "tumor cerebral maligno". Trêmulo, senti meu corpo

\footnotetext{
${ }^{8} \mathrm{O}$ glioblastoma multiforme (GBM), também conhecido como glioblastoma e astrocitoma grau IV, é o tipo mais comum e agressivo de tumor maligno cerebral que acomete os seres humanos. Os sinais e sintomas iniciais são inespecíficos e podem incluir cefaleia, alterações de personalidade, náuseas e sintomas similares aos de um acidente vascular cerebral. O agravamento dos sintomas é geralmente rápida, podendo evoluir para um quadro de inconsciência.
} 
gemer a anúncio da morte dela. O câncer era para mim, metáfora da morte. Após sentar num banco qualquer, voltei a leitura do exame. As palavras embaralhadas, emaranhavam meus sentimentos. Li sobre a forma do corpo estranho que a matava pouco a pouco: "espécime em formalina medindo 5, 0 × 3,5 ×3,0, castanho-acinzentados e macios". Me questionei como um corpo disforme, sem cores vivas podia ser tão nociva a vida. Tínhamos agora a certeza de que o câncer havia se apoderado de seu corpo. Iniciamos a batalha contra ele. Metáfora bélica em defesa da vida.

Os diagnósticos não eram favoráveis. Sejam quais fossem os médicos - neurologistas, oncologistas, clínicos especializados em radiologia -, os discursos de pavor foram os mesmos: com o imediato tratamento, a "sobrevida é de poucos meses"; "quatro ou cinco meses". O tempo, o câncer e o desespero eram nossos inimigos. Corríamos na contra mão. $\mathrm{O}$ tratamento a ser iniciado era o mesmo aplicado a quaisquer portadores de câncer: radioterapia e quimioterapia. Seu corpo seria submetido a agressividade da medicina.

As previsões dos médicos pareciam revelar a certeza da morte. Eram os donos da verdade. Ditavam prazos para que contássemos os dias que lhe restavam de vida. Médicos que, pareciam ainda não ter aprendido que "nada no homem - nem mesmo seu corpo é bastante fixo para compreender outros homens" (FOUCAULT, 2009, p. 27), que cada história é individual, que uma doença como o câncer "nada significava ao saber arrogante do hospital, impotentes diante da doença" (FOUCAULT, 2009, p. 27).

Seu nome já causava pavor. Ao longo do tempo, o câncer foi definido como "um inchaço, um caroço, ou uma protuberância" (SONTAG, 2007, p. 16). Uma enfermidade que teve seu nome batizado por Galeno, ao associar a doença as patas de um caranguejo e as veias inchadas de um tumor externo. Passou a ser vista como uma doença que tudo irrita, corrói, corrompe ou consome, lentamente e em segredo. Moléstia de "crescimento (as vezes visível; mais tipicamente interno), de um crescimento anormal e em última instancia letal" (SONTAG, 2007, p. 17); silenciosa, pôr nem sempre apresentar sintomas aparentes; mortal, pôr na maioria dos casos já ser descoberta em estágio muito avançado. Uma acharque da deformidade, da degeneração dos tecido do corpo, do endurecimento e necrosamento das células vivas, uma massa de granito que rasteja dentro do corpo, uma gravidez maldita, feto demoníaco que possui vontade própria, gangrena parasitária que come o corpo, concreto da 
morte, células alienígenas que atrofiam e murcham a vida, enfermidade traiçoeira, amputação de sonhos, mutilação de histórias, fendas nas memórias.

A doença, responsável por desorganizar nossas vidas, exigia uma reorganização, uma nova forma de sentir, de encarar a vida. Um acontecimento mórbido que tornava-se lugar privilegiado para observar a reorganização da vida a partir do caos estabelecido (Cf. PETER; REVEL, 1976). As mazelas trazidas em seu corpo nos levaram até o Hospital Napoleão Laureano ${ }^{9}$, especializado em tratamento do câncer. As memórias daquele lugar são doloridas. Lembro da porta que se abria nos levando até o saguão, em que a partir dele seguíamos por um corredor até a sala da médica responsável pela radioterapia. Condenada a trinta sessões radioterápicas, alegado como sendo a carga máxima suportada pelo corpo humano, seu corpo precisava diariamente daqueles raios que visavam bloquear o crescimento do tumor, ao menos por um tempo. Em conversa com a médica, lembro de afirmativas severas que não combinavam com a aparência doce daquela profissional: “[...] o tratamento vai bloquear por um tempo a ação danosa do tumor, porém depois de um certo tempo, cerca de meses, a radioterapia não mais fará efeito" [espasmos] "é provável que ela tenha outro AVCH, fatal, ou que o crescimento do tumor atinja espaços do cérebro que façam com que cada parte de corpo pare de funcionar". A maldição estava lançada!

Saí daquela sala fazendo-me de forte e segurando suas mãos. Os passos eram lentos. Sentia o horror e visualizava o pavor. Corpos por todos os lados costurados, remendados ou mesmo amputados. Buracos abertos. Fissuras rasgada nos corpos e que podiam ser vistas de longe. Humores nada agradáveis ao olfato. Questionei-me se realmente aquelas pessoas estavam vivas, ou se num pesadelo, apareciam em minha frente imagens de zumbis deformados, desfigurados, alterados, corrompidos, mutilados, sem cor. Era real. Era o espaço historicamente construído para os relegados a doença. Espaço da pedagogia do dor. Lugar em que a disciplina não mais fazia sentido.

Doenças como o câncer "quando não mataram de imediato, sempre transformaram jovens ou na força da idade em velhos" (BECKER, 2009, p. 435). Ela promovia o

\footnotetext{
${ }^{9}$ Foi fundado em 24 de fevereiro de 1962 na gestão de Pedro Gondim, então governador do estado da Paraíba. O Hospital Napoleão Laureano possuía cinquenta leitos, bloco cirúrgico com três salas de cirurgia, laboratório de análises clínicas, laboratório de anatomia patológica, serviço de radiologia, dentre outros. Atualmente, é especializado no tratamento do câncer, disponibilizando atendimento de radioterapia e quimioterapia, além de cirurgias especificas para retirada de tumores.
} 
envelhecimento acelerado do corpo, deixando a "pele flácida, enrugada, amarelada e ressecada, coberto com todo tipo de abcessos, machas escuras, rachaduras, fendas, rugosidades, escamas" (BECKER, 2009, p. 435). A ação da doença causou no corpo dela, todos os dias uma novidade, uma nova deformidade: os cabelos que restavam ficaram mais brancos, os dentes caíram, manchas escuras pareciam por todo seu corpo, as pele fina e engelhada mostrava as cores verdes desmaiadas das veias já altas de tanto serem furadas.

Os escritos de David Le Breton (2003), antes de dar "adeus ao corpo", registrou que as pessoas passaram a ser aquilo que se é corporalmente. Sua identidade confunde-se com seu corpo, ao mesmo tempo em que essa configuração corporal tornou-se algo transitório, que deveria estar constantemente sendo modificada. Essa assertiva descreve bem a relação entre a identidade que se constitui durante a vida e as transformações ao qual o corpo foi submetido. Nesse caso, em específico, o corpo daquela mulher alta e altiva que cuidou de si e da estética de sua existência, foi deflorado pela doença, construindo um corpo considerado repugnante aos olhos da "normalidade", pois a "deformidade perturba a imagem da integridade corporal" (COURTINE, 2009, p. 277). O câncer modificou o corpo. O tratamento contra o câncer, contribuiu na construção do anormal: uma apresentação do horror.

Os meses de janeiro e fevereiro foram seguidos de visitas diárias aquele lugar cinza. A sala de porta larga, verde e fria, era repleta de imagens de campos, de flores, jardins. Ao questionar a razão daquelas pinturas feitas nas paredes, a enfermeira respondeu que tinha a função de fazer o paciente sentir-se bem, de imaginar-se naquele lugar. De imediato, senti a metáfora da imagem daquilo que historicamente se construiu sobre o céu: o imenso pomar da paz. Percebi aquilo como uma espécie de conformidade ao destino que esperava o enfermo: a morte. Uma tentativa de fazê-la aceitar o futuro que se aproximava. Metáfora do paraíso.

Deitada numa mesa verde, seu corpo já quase esquelético, recebeu uma máscara que mais parecia uma rede de pescar. O material plástico que a formava tinha o formato do tecido que se lança ao mar. Presa pela máscara, amarrada pelas mãos e pelos pés, os fios de laser vermelho eram metricamente posicionados sob os pontos marcados na máscara que envolvia sua cabeça. Com tudo preparado, saíamos da sala. De fora, esperávamos os minutos da aplicação dos raios que invadiam seu corpo. Foram trinta seções. A cada uma delas, seu corpo 
desfigurava-se mais. Pouco a pouco, os fios de cabelos que ainda restavam, foram caindo. Seu sorriso, também desaparecia.

Enquanto as seções de radioterapia eram diárias, as de quimioterapia eram quinzenais. Os médicos optaram por aplicar via oral. O Temodal, medicamento receitado pelo oncologista, precisava ser tomado sempre na primeira e na terceira semana de cada mês. Eram capsulas que vinham em vidros. Gelatinosas e bastante onerosas. A dose quinzenal era bastante alta. Devido à dificuldade de conseguir o medicamento, muitas vezes só conseguíamos comprar comprimidos de 5 a 10 miligramas. A soma deles deveria resultar no valor de 350 miligramas. Tinham que ser deglutidos com água. Muitas vezes, lembro de juntar minhas mãos e enche-las de capsulas que deveriam por elas ser tomadas. Passados trinta a quarenta minutos de sua ingestão, as reações pavorosas apoderavam-se de seu corpo: os vômitos. Houveram dias, em que faltava coragem para fazê-la tomar a quimioterapia, a desilusão sobre a vida se abatia. Então, fechava os olhos, respirava, pensava que daquela vez as reações não seriam tão violentas. Me enganava.

Com o término da radioterapia, ela passou a ser acompanhada por um oncologista que mesmo sendo portador de verdades cruéis, sempre nos atendia com sorriso e esperança. Ela dizia que ele parecia um bom moço, mas não gostava de encontrar com ele. 0 último laudo escrito a punho entregue pelo médico oncologista declarava que "Maria de Fátima do Nascimento Santos era portadora de CID10 C. $71^{10}$, doença bastante avançada, sem perspectiva de cura. Necessita em função das limitações decorrentes de sua doença, auxílio constante e contínuo por tempo indeterminado" (Laudo médico, 29 set. 2011). Estava escrito pelos donos do saber médico que a cura não mais existia. Naquele caso, tiveram razão.

Passados os dois primeiros meses, o tratamento parecia surtir efeitos antes considerados impossíveis pelos médicos. As dores haviam diminuído consideravelmente, o apetite aos poucos dava sinal de retorno, os cabelos voltaram a brotar, o sorriso, ainda que desfigurado, meio que de canto de boca, aparecia. O segundo semestre daquele ano de dois mil e onze, foi o momento em que o aproveitar a vida, teve seu maior sentido. As seções de quimioterapia continuavam. Pouco a pouco, ganhamos um novo ritmo de vida, a doença nos obrigou a ressiginificar nossa existência, não sei se existia mais uma boa estética de si para

\footnotetext{
${ }^{10}$ Neoplasia maligna do encéfalo.
} 
aquele corpo, mas soube naquele momento o que era a estética do amor, da gratidão a Deus pela sobrevida, das novas formas de conduzir nossas histórias, das fatias de bolo comidas com a mão, das longas horas de sono dela sem a preocupação com as atividades do dia seguinte, das engraçadas lembranças que vez em quando saltavam como luminosidades em sua memória, dos personagens que ela imaginou ser, da mãe que acreditava ainda ter, dos filhos que afagava com aquelas mãos envelhecidas pela ação da doença. Uma estética da vida.

Estética interrompida. A execrável doença logo voltou a ganhar força. Fez crescer seus tentáculos deformando seu corpo e ceifando sua vida. Foi assim desde o início do ano de dois mil e doze. Nossos momentos de felicidade deram lugar ao silêncio. A maldição recitada pela médica, há um ano, ganhava poder: seu corpo disforme ganhava outras deformidades. Nunca foi bailarina, mas seu corpo se torceu e contorceu, revirou, deu voltas sem volta. Seus braços giraram ao avesso dando uma volta de 180 graus. Suas pernas atrofiaram. Seus olhos azuis ficaram cinzas, escuros. O controle do sistema renal e intestinal foi perdido. Seus ouvidos pareciam nãos mais ouvir. Seu sono era profundo. Seu corpo secou. Sua boca fechou-se. Foi só silêncio. Corpo espetacularmente deplorável.

No amanhecer do dia dezessete de julho de 2012, ela me fitou, tentou sorrir. A abracei envolvendo em meus braços. Fechou os olhos e partiu.

\section{REFERÊNCIAS BIBLIOGRÁFICAS}

FONTES

Atestado Médico. Arquivo pessoal do autor. João Pessoa, 28 de setembro de 2010.

Exame anatomopatológico. Arquivo pessoal do autor. João Pessoa, 05 de janeiro de 2011.

Laudo médico. Arquivo pessoal do autor. João Pessoa, 29 de setembro de 2011.

Ressonância magnética do encéfalo. Arquivo pessoal do autor. João Pessoa, 20 de dezembro de 2010. Tomografia computadorizada de crânio. Arquivo pessoal do autor. João Pessoa, 23 de setembro de 2010.

Tomografia cerebral. Arquivo pessoal do autor. João Pessoa, 18 de dezembro de 2010.

\section{BIBLIOGRAFIA}

ALBUQUERQUE JÚNIOR, Durval Muniz. Escrever como o fogo que consome: reflexões em torno do papel da escrita nos estudos de gênero. Disponível em: simposioufac.blogspot.com.br/2013/07/durval-muniz-de-albuquerque-junior_22.html. Visita em 27 de outubro de 2017. 
BECKER, Annette. Extermínios - o corpo e os campos de concentração. In.: CORBIN, A.; COURTINE, JJ.; VIGARELLO, G.. História do corpo. Petrópolis: Vozes, 2009, p. 417-443.

BRETON, David Le. Adeus ao corpo: antropologia e sociedade. Campinas: Papirus, 2003.

CORBIN, Alain. Dores, sofrimentos e miséria do corpo. In: CORBIN, A.; COURTINE, JJ.; VIGARELLO, G.. História do corpo. Petrópolis: Vozes, 2008, p. 267-345.

COURTINE, Jean-Jacques. O corpo anormal. História e entropologia culturais da deformidade. In.: CORBIN, A.; COURTINE, JJ.; VIGARELLO, G.. História do corpo. Petrópolis: Vozes, 2009, p. 253-340.

FALEIRO, Rodrigo Moreira et all. Craniotomia descompressiva para tratamento precoce da hipertensão intracraniana traumática. Arq Neuropsiquiart, São Paulo, n. 63, p 508-513, 2005.

FARGE, Arlete. O sabor do arquivo. São Paulo: USP, 2017.

FOUCAULT, Michel. Eu, Pierre Rivière, que degolei minha mãe, meinha irmã e meu irmão. Rio de Janeiro: Graal, 2003.

. Vigiar e punir. Petrópolis: Vozes, 2009.

. A microfísica do poder. São Paulo: Graal, 2009.

GRIGÓRIO, Tamires Emanuele Lopes. Serviço de arquivo médico e estatística do Hospital Estadual de Emergência e Trauma Senador Humberto Lucena na perspectiva dos seus usuários. João Pessoa, 2005, 60 p. Monografia (Graduação em Arquivologia), Centro de Ciências Sociais e Aplicadas, Universidade Federal da Paraíba.

LAVILATTE, Marie-Jeanne. Le privilège de la puissance. Universidade Paris I, 1999.

PESAVENTO, Sandra Jatahy. História e História Cultural. Belo Horizonte: Autêntica, 2005, p. 15.

. Sensibilidades: escrita e leitura da alma. In: PESANVENTO, Sandra Jatahy; LANGUE, Frádérique. Sensibilidade na história: memórias singulares e identidades sociais. Porto Alegre: UFRGS, 2007, p. 922.

PETER, Jean-Pierre; REVEL, Jacques. O corpo: o homem doente e sua história. In: LE GOFF, Jacques. História - Novos objetos. Rio de Janeiro: Francisco Alves, 1976.

POE, Edgar. Histórias extraordinárias. São Paulo: Martins Fontes, 2015.

NORA, Pierre. Ensaios de ego-história. Lisboa: Edições 70 Ltda., 1989.

SONTAG, Susan. Doença como metáfora. Rio de Janeiro: Companhia de Bolso, 2007.

TÉTART, Philippe. Pequena história dos historiadores. São Paulo: EDUSC, 2000. 